\title{
DECIMAL SYSTEM FOR \\ CLASSIFYING DATA \\ PERTAINING TO THE \\ PETROLEUM INDUSTRY
}

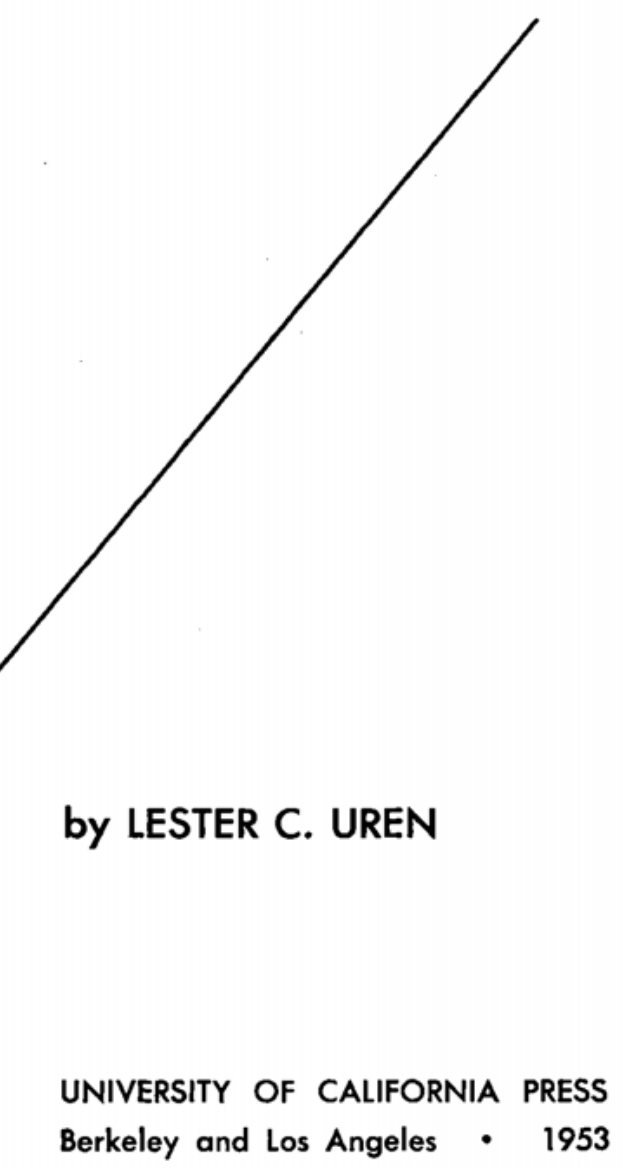




\section{UNIVERSITY OF CALIFORNIA PRESS BERKELEY AND LOS ANGELES \\ CALIFORNIA}

CAMBRIDGE UNIVERSITY PRESS

LONDON, ENGLAND

COPYRIGHT, 1953, BY

THE REGENTS OF THE UNIVERSITY OF CALIFORNIA

PRINTED IN THE UNITED STATES OF AMERICA 